\title{
IMPACTOS EDUCACIONAIS E SOCIOCULTURAIS NA EDUCAÇÃO BÁSICA: estudo de caso sobre a implantação de uma Comissão Própria de Avaliação
}

\begin{abstract}
DENISE ALVES LUCENA
Mestre em Educação pelo Programa de Pós-Graduação em Educação PPGE-UPE (2019). Especialista em Gestão Pública (IFPE, 2013) e em Língua Portuguesa (FAINTVISA, 2009). Graduada em Letras (UPE, 2007). Professora de Língua Portuguesa da Secretaria Estadual de Educação de Pernambuco desde 2010. Membro do Grupo de Estudos e Pesquisa em Políticas Educacionais, Sujeitos, Docência e Currículo (POSDOC) da Universidade de Pernambuco. Gestora da Escola Estadual Antônio Inácio desde 2014. ORCID: 0000-0002-3354-8633.

E-mail: denisealvesdelucena@gmail.com
\end{abstract}

\section{DORIELE SILVA ANDRADE COSTA DUVERNOY}

Universidade de Pernambuco (UPE). Doutora em Educação (Université Lumière Lyon 2 França, 2012) com período sanduíche no PPGE-UFPE. Mestrado em Educação (Université Lumière Lyon 2, 2008). Graduada em Pedagogia (UFPE, 2005). Professora Adjunta da Universidade de Pernambuco - UPE. Líder do Grupo de Estudos e Pesquisa em Políticas Educacionais, Sujeitos, Docência e Currículo (POSDOC). Coordenadora do Programa de Pósgraduação - Mestrado Profissional em Educação- PPGE-UPE. ORCID: 0000-0002-6984-4012. E-mail: doriele.andrade@upe.br 


\section{IMPACTOS EDUCACIONAIS E SOCIOCULTURAIS NA EDUCAÇÃO BÁSICA: estudo de caso sobre a implantação de uma Comissão Própria de Avaliação}

Este artigo traz uma discussão sobre a qualidade da educação básica, especialmente, dos termos dimensões, parâmetros e indicadores, articulados entre si, a partir dos quais se materializam políticas públicas educacionais para avaliar e monitorar a qualidade da educação escolar. De abordagem qualitativa, articulando os aspectos teórico-metodológicos da pesquisa ação e de estudo de caso, esta pesquisa teve como objetivo investigar, a partir da implantação e implementação de uma comissão própria de avaliação (CPA), os indicadores alternativos propostos pela comunidade escolar para monitorar e avaliar a qualidade da educação em uma escola da rede estadual de ensino, situada em Feira Nova, através da construção de quarenta indicadores alternativos e seus respectivos parâmetros, subdivididos em dez dimensões. Esta pesquisa não substitui ou desconsidera as avaliações em larga escala, mas possibilita a articulação dos indicadores próprios de avaliações externas a indicadores alternativos criados pela CPA, para avaliar a qualidade da educação ofertada pela instituição de ensino em questão. Como resultados obtidos, foi possível elencar os impactos educacionais e socioculturais oriundos da implantação e implementação desta CPA.

Palavras-chave: Qualidade da Educação. Avaliação da Educação Básica. Gestão Escolar. Autoavaliação Institucional. Comissão Própria de Avaliação.

\section{IMPACTOS EDUCATIVOS Y SOCIOCULTURALES EN LA EDUCACIÓN BÁSICA: un estudio de caso sobre la implementación de un Comité de Evaluación}

Este artículo analiza la calidad de la educación básica, especialmente los términos dimensiones, parámetros e indicadores, articulados entre sí, a partir de los cuales se materializan las políticas educativas públicas para evaluar y monitorear la calidad de la educación escolar. Con un enfoque cualitativo, articulando los aspectos teóricos y metodológicos de la investigación de acción y el estudio de caso, esta investigación tuvo como objetivo investigar, desde la implementación y la implementación de un comité de evaluación propio (CPA), los indicadores alternativos propuestos por la comunidad escolar supervisar y evaluar la calidad de la educación en una escuela estatal, ubicada en Feira Nova, mediante la construcción de cuarenta indicadores alternativos y sus respectivos parámetros, subdivididos en diez dimensiones. Esta investigación no reemplaza ni hace caso omiso de las evaluaciones a gran escala, pero permite la articulación de los indicadores de evaluaciones externas a indicadores alternativos creados por el CPA, para evaluar la calidad de la educación ofrecida por la institución educativa en cuestión. A medida que se obtuvieron los resultados, fue posible enumerar los impactos educativos y socioculturales derivados de la implementación y la implementación de este CPA.

\section{plurais}


Palabras-clave: Calidad de la educación. Evaluación de educación básica. Gestión escolar. Autoevaluación institucional. Comité de evaluación propio.

\section{EDUCATIONAL AND SOCIOCULTURAL IMPACTS ON BASIC EDUCATION: a case study on the implementation of an own Evaluation Committeen}

This article discusses the quality of basic education, especially the terms dimensions, parameters and indicators, articulated among themselves, from which public educational policies materialize to assess and monitor the quality of school education. With a qualitative approach, articulating the theoretical and methodological aspects of action research and case study, this research aimed to investigate, from the implementation and implementation of an own evaluation committee (CPA), the alternative indicators proposed by the school community for monitor and evaluate the quality of education in a state school, located in Feira Nova, through the construction of forty alternative indicators and their respective parameters, subdivided into ten dimensions. This research does not replace or disregard the large-scale assessments, but it does allow the articulation of the indicators from external assessments to alternative indicators created by the CPA, to assess the quality of education offered by the educational institution in question. As results obtained, it was possible to list the educational and socio-cultural impacts arising from the implementation and implementation of this CPA.

Keywords: Quality of Education. Basic Education Assessment. School management. Institutional SelfAssessment. Own Evaluation Committee. 


\section{IMPACTOS EDUCACIONAIS E SOCIOCULTURAIS NA EDUCAÇÃO BÁSICA: estudo de caso sobre a implantação de uma Comissão Própria de Avaliação}

\section{Introdução}

Com a implantação e implementação de uma Comissão Própria de Avaliação (CPA) em uma escola da rede estadual de ensino, pretende-se que a noção de qualidade da educação, desta instituição de ensino, passe a ter uma ressignificação que vá além dos muros da escola e da mera transmissão de conteúdo.

Essa ressignificação deve propiciar que a escola seja vista como um espaço de aprendizagem sintonizado com a comunidade escolar, com o meio em que os sujeitos, que dela fazem parte, possam construir com autonomia e, em cooperação, com seus conhecimentos e sua própria história.

A nossa atuação na gestão de uma escola da rede estadual de ensino, localizada no município de Feira Nova - PE foi determinante para a escolha do tema e da escola que é o lócus desta pesquisa, pois nela, compartilhamos os desafios cotidianos de professores, alunos e comunidade escolar, bem como a possibilidade de sensibilizar e apoiar estes sujeitos a buscarem soluções para esses desafios que constituem problemas na escola.

Diante disso, acreditamos que a qualidade da educação de uma instituição de ensino está atrelada aos resultados de avaliações internas e externas, mas que há, também, outros indicadores educacionais que não são considerados pelas avaliações externas e que podem ser importantes para melhorar a qualidade da educação ofertada na escola.

Por isso, surge a necessidade de se pensar, junto à comunidade escolar, novos indicadores educacionais, a fim de que os sujeitos deste lócus de pesquisa modifiquem a sua realidade a partir da reflexão e ação, comprometidos com a qualidade da educação ofertada à sociedade.

Partindo dessa perspectiva, este texto visa a apresentar a nossa pesquisa, de abordagem qualitativa e com base na pesquisa-ação cujo objetivo foi investigar, a partir da implantação e implementação de uma comissão própria de avaliação, os indicadores alternativos propostos pela

\section{plurais}


comunidade escolar para monitorar e avaliar a qualidade da educação em uma escola da rede estadual de ensino, situada em Feira Nova - PE.

Mais especificamente, buscamos discutir sobre o Índice de Desenvolvimento da Educação Básica de Pernambuco - IDEPE como parâmetro de rendimento dos estudantes em relação aos resultados desejados e obtidos nas escolas da rede estadual de Pernambuco, sobre as concepções e os parâmetros da qualidade total, da qualidade social e qualidade negociada da educação; conhecer a percepção dos sujeitos da pesquisa sobre a avaliação externa, acompanhamento e avaliação da qualidade da educação realizada pela escola; criar uma CPA que debata e aponte estratégias para a elaboração de uma proposta alternativa de monitoramento de qualidade em educação na escola; verificar as articulações possíveis entre os resultados obtidos pelos indicadores do IDEPE e pelos indicadores próprios, fomentados pela CPA para acompanhamento do desempenho da escola.

No decorrer da pesquisa, levantamos discussões acerca da qualidade total da educação, a qual visa à eficiência (custo-benefício) e à eficácia (resultado), em contrapartida, relacionamos este tipo à qualidade social e à qualidade negociada. A primeira se caracteriza por ter uma abordagem mais democrática e popular, pois busca a formação humana, o direito à cidadania, ou seja, a formação integral do ser. A segunda visa ao apoio a processos de mudanças complexas dentro da escola. Ambas se assemelham ao pressuporem mais um princípio: a efetividade, o qual além de unir os princípios da eficiência e da eficácia, aponta o impacto que as ações de melhoria podem exercer para transformar a situação existente no âmbito escolar. (MEZOMO, 1997; ZITKOSKI, 1997; HERÉDIA, 1997; DOURADO, 2007; FREITAS, 2005; BONDIOLI, 2005; PERONI, 2006; MARCHART, 2007; BRASIL, 2010).

Essa discussão nos permite constatar a magnitude do termo qualidade da educação por ser mais complexo que compreender o sentido de qualidade isoladamente. É por isso que a qualidade da educação não dever ser vista sob apenas uma perspectiva, ela deve estar relacionada a valores, tradições, conhecimentos científicos, contexto histórico, social e econômico, bem como à missão de cada instituição. Assim, a qualidade da educação deve atrelar, além de resultados de avaliações externas, a autoavaliação escolar, as vivências intra e extraescolares. Só assim a qualidade da educação atinge a totalidade do seu significado.

\section{plurais}


Logo, esse enfoque faz emergir a qualidade como uma política educacional, já que desenhar uma política pública que garanta uma educação de qualidade a todos os cidadãos é considerar os anseios e necessidades dos sujeitos envolvidos no processo educativo.

Com as reformas educacionais na década de 1990, houve um enfoque voltado à melhoria da qualidade da educação brasileira, visto que muito se discutiu acerca dos problemas de desigualdade no acesso à escolarização, das elevadas taxas de reprovação, de evasão escolar e, no decorrer dos anos, essas discussões sobre a qualidade da educação enveredaram por diversos prismas.

Em contraponto à qualidade total, a qualidade social e a qualidade negociada implicam na negociação entre os sujeitos envolvidos no processo educativo, quando coloca a possibilidade de participação como direito dos sujeitos para que possam melhorar a própria vida e a do meio onde vivem.

Assim, considerando o impacto que a centralidade do IDEPE, enquanto diretriz da política educacional voltada à melhoria da qualidade da educação da rede estadual de ensino do Estado de Pernambuco, como também a implantação e implementação de uma CPA em uma escola desta rede de ensino, interrogamo-nos: quais os indicadores alternativos de avaliação e monitoramento da qualidade da educação emergem a partir da criação de uma CPA na escola? Quais os impactos poderiam ser observados na escola se os próprios sujeitos da escola elaborassem seus parâmetros de qualidade para compor uma avaliação própria? Quais as possíveis articulações entre o índice de desenvolvimento implementado nesta pesquisa-ação e os resultados obtidos no IDEPE?

Essas questões norteadoras oportunizam a construção de indicadores alternativos para avaliar e monitorar a qualidade da educação nas escolas, pautada numa perspectiva crítico-reflexiva, através do processo que permitiu a CPA elaborar indicadores de qualidade em educação a partir de dez dimensões.

Do ponto de vista metodológico, este trabalho seguiu orientação de cunho qualitativo com base nas orientações de Minayo (2001), Goldenberg (1997) e Duarte (1998), seguindo os princípios da pesquisa-ação a partir de Fonseca (2002), Thiollent (2011) e Chisté (2016). A investigação foi realizada por meio de estudo de caso e conduzida pelas concepções de Doley (2002), Latorre et al. (2003), Yin (2005) e Yacuzzi (2005). A principal técnica de coleta de dados ocorreu através de

\section{plurais


grupo focal (GOMES E BARBOSA, 1999; FLICK, 2002; GONDIM, 2002; GASKELL, 2002). Como instrumentos complementares à coleta de dados, utilizamos as técnicas de observação participante e a entrevista semiestruturada (FLICK, 2004) durante os encontros do grupo focal.

Devido ao cotidiano escolar estar intrínseco ao objeto de estudo desta pesquisa, os sujeitos participantes do grupo focal foram selecionados de forma a representar os segmentos da comunidade escolar, tais como "alunos, professoras (...) tantos outros que "vivem" as escolas", a fim de "escutar os sujeitos das escolas para, a partir dessa escuta e com eles, fortalecer processos contra hegemônicos de políticas educacionais cotidianas” (FERRAÇO, 2007, p.03).

Ao propor escutar os sujeitos da escola, para, assim, fortalecer processos contra hegemônicos de políticas educacionais, além da escolha de sujeitos pertencentes à comunidade escolar, das técnicas utilizadas nas reuniões do grupo focal, emergiram, durante as reuniões, as seguintes subtemáticas para discussão: qualidade da educação e função social da escola, tipo de resultados esperados pela escola, pontos positivos e problemas enfrentados na/pela escola e a construção de novas dimensões para autoavaliação da qualidade da educação.

Os subtemas tornaram-se categorias de análise que, por sua vez, puderam contribuir na concepção de conceitos pontuais, discutidos ao longo da pesquisa, bem como de dados empíricos que puderam auxiliar na composição de dimensões, parâmetros e indicadores alternativos.

\section{O Sistema Educacional Brasileiro e a Qualidade da Educação}

Antonio Chizzotti (2020), em pesquisa realizada sobre as finalidades dos sistemas de educação brasileira, analisa a educação escolar através de três finalidades definidas pela Constituição Brasileira (1988): o pleno desenvolvimento da pessoa, o preparo para o exercício da cidadania e a qualificação para o trabalho. Na pesquisa, ele discorre sobre o impacto social da educação e seus efeitos sociais, tanto para a vida do indivíduo-cidadão, quanto para o conjunto da sociedade.

Sob este ponto de vista, a finalidade da escola adentrou ao discurso local e atualizou os acordos e as divergências sobre os objetivos e as possibilidades atuais da educação nos estados democráticos em todo o mundo.

\section{plurais}


O Estado democrático pressupõe uma escola democrática: uma escola que deve dar a todos as capacidades intelectuais e éticas necessárias para se formar, como pessoa-cidadã e participar da vida pública (CHIZZOTTI, 2020, p.10).

Para ele, os sistemas de educação foram profundamente convulsionados pelas novas exigências sociais e culturais e, por este motivo, tornaram-se objetos de críticas e proposições sobre as muitas orientações e atividades da escola, que revelam a sobreposição de projetos governamentais, uma difusão de objetivos e a ausência de consensos sobre as finalidades atuais da educação escolar.

As considerações de Chizzotti (2020) pressupõem que as finalidades do sistema educacional, na prática, não contemplam as necessidades do estudante, não corroboram com a Constituição Federal e, por este motivo, a qualidade da educação fica comprometida.

A escola, para Chizzotti (2020, p.10),

(...) não está isenta, nem imune ao seu contexto social. Ela depende das condições econômicas e políticas do Estado no qual está inserida. Essas condições são determinantes para alcançar ou limitar o alcance das finalidades, constitucionalmente expressas do sistema de educação.

Pensar a escola por esse prisma nos leva a considerar que a discussão sobre a finalidade do sistema educacional é indissociável das discussões sobre a qualidade da educação.

Neste sentido, o sistema educacional brasileiro legitimou-se com a aplicação de avaliações em larga escala em todo o território nacional, para que houvesse um parâmetro para a qualidade da educação.

A questão da qualidade da educação está presente na atual Constituição Federal (CF), pela garantia do padrão de qualidade (Art. 205), indicando a avaliação de qualidade pelo poder público como condição ao ensino livre à inciativa privada (Art. 209), e pela melhoria da qualidade do ensino (art. 214). Isso é uma importante conquista, já que a Constituição Federal de 1967, embora reconhecesse o papel da educação enquanto direito (Art. 168), delimitasse a competência da união em estabelecer planos nacionais de educação e de saúde, assim como as diretrizes e bases da educação nacional; $\left(\right.$ Art. $\left.8^{\circ}\right)$; e que cada ente federativo assegurassem condições de eficiência escolar (art.169), não explicitava o debate sobre qualidade da educação.

\section{plurrais Savador v.5, n.1 p.261-284, jan/abr 2020}


Com a LDB de 1996, a avaliação nacional é atribuída como papel da União, que deve "coletar, analisar e disseminar informações sobre a educação" e assegurar o processo "[...] em colaboração com os sistemas de ensino, objetivando a definição de prioridades e a melhoria da qualidade do ensino" (Art. 9, V, VI, respectivamente). (COSTA, 2019)

Dessa maneira, as implicações desses sistemas não se limitam a gestão escolar e educacional, mas alargam as possibilidades do uso dos indicadores tanto para aferir a qualidade da educação como para responsabilizar quem faz educação.

Dourado (2007), ao utilizar o termo qualidade da educação, elucida que este termo "não pode ser reduzido à rendimento escolar, nem tomado como referência para o estabelecimento de mero ranking entre as instituições de ensino."

Pensar em qualidade da educação meramente como rendimento escolar ou ranqueamento de instituições de ensino, leva-nos a discutir acerca de três conceitos de qualidade da educação.

Mezomo (1997), a partir das discussões de Crosby (1990), Juran (1990), Deming (1990) e Donabedian (1991), percebem a qualidade total da educação como um ponto de referência para os sistemas de avaliações em larga escala por trazer características como esforço, renovação e inovação; ao passo que Zitkoski (1997) discute a qualidade total da educação como tecnificação do conhecimento, burocratização do sistema e atrofiamento da capacidade crítica do ser humano.

Contrapondo a ideia de qualidade total, a qualidade social da educação, discutida por Peroni (2006) e Dourado (2007), caracteriza-se por ser democrática e popular ao assegurar um processo pedagógico que vise à melhoria das condições de aprendizagem do educando articulada a melhores condições de vida e formação da população. A qualidade social da educação assemelha-se à qualidade negociada (FREITAS, 2005) por criar compromissos ancorados na comunidade escolar.

Assim, em contraponto à qualidade total, a qualidade social e a negociada implicam na negociação entre os sujeitos envolvidos no processo educativo, conforme corrobora Dourado (2007) ao tratar a qualidade social da educação como:

(...) um conjunto de fatores intra e extraescolares que se referem às condições de vida dos alunos e de suas famílias, ao seu contexto social, cultural e 
econômico e à própria escola - professores, diretores, projeto pedagógico, recursos, instalações, estrutura organizacional, ambiente escolar e relações intersubjetivas no cotidiano escolar. (DOURADO, 2007, p. 941)

Os fatores intra e extraescolares, descritos por Dourado (2007) para garantir uma qualidade social da educação, estão intrínsecos às finalidades dos sistemas de educação, descritos na Constituição Federal (1988) acerca dos sistemas de educação brasileira.

A educação escolar continua sendo um campo de contradições permanentes entre projetos políticos e projetos de vida. Esse contraste se reflete quando notamos que os projetos políticos priorizam os resultados numéricos, já que nas avaliações externas e nos índices educacionais é cobrada a excelência, enquanto que o projeto de vida, por sua vez, requer, além de resultados de excelência, o impacto social da educação escolar na vida do estudante. Isso aponta que há predominância da qualidade total da educação nos projetos políticos e da qualidade social nos projetos de vida.

Logo, é possível pressupor que quando os sistemas de educação obtêm êxito, nem sempre a qualidade social da educação acontece. Por isso, a necessidade de assegurar uma qualidade social da educação.

Assim, para assegurar discussões sobre a qualidade da educação na escola, lócus da pesquisa, foi necessária a implantação e implementação de uma CPA para que houvesse reflexões, planejamentos, ações e avaliações com vistas a garantir o processo de escuta dos sujeitos envolvidos na pesquisa. E, em decorrência desse processo, emergem a qualidade negociada e qualidade social da educação durante o processo de elaboração de uma autoavaliação da unidade escolar com a finalidade de avaliar a qualidade da educação.

\section{Comissão Própria de Avaliação: um subgrupo do Conselho Escolar de uma escola da rede estadual de ensino}

Em meio aos diversos sistemas de avaliação que existem, atualmente, para todos os níveis e modalidades de ensino e levando em conta toda a complexidade envolvida no processo de avaliação de uma escola, especialmente, no contexto do IDEB e IDEPE, surge a necessidade da criação e do desenvolvimento de dispositivos de autoavaliação como proposta para melhorar/garantir a qualidade da educação das escolas.

\section{plurais


A autoavaliação de uma instituição de ensino da educação básica não se reduz à atribuição de notas, infraestrutura e atividades extracurriculares e, muito menos, à definição de um diagnóstico revelado por números. Uma unidade educacional desenvolve suas atividades norteadas por uma filosofia educacional exposta em sua missão e descritas no seu Projeto Político Pedagógico (PPP), o qual resulta de um amplo processo de estudo e reflexões que vincula e reflete o entorno social, a comunidade escolar.

No estado de Pernambuco, o Art. $2^{\circ}$ da Lei no 11.014 de 28 de dezembro de 1993 dispõe sobre a criação dos Conselhos Escolares nas Escolas da Rede Estadual de Ensino e indica que este órgão colegiado tem como finalidade zelar pela qualidade da educação escolar oferecida à população (inciso II), garantir a articulação da escola com a comunidade (inciso III) e visa a ajustar as diretrizes e metas estabelecidas pela Secretaria de Educação Cultura e Esportes à realidade da Escola (inciso VII). (PERNAMBUCO, 1993).

Devido a essas finalidades, o Conselho Escolar é considerado uma instância propícia à criação de um subgrupo denominado de Comissão Própria de Avaliação (CPA) com a incumbência de autoavaliar a qualidade da educação da escola com atribuições consultivas, propositivas e de assessoria sobre matéria de natureza avaliativa.

Assim, a CPA foi composta por professores, estudantes e membros da equipe gestora (escolhidos através de eleição, após apresentação ao Conselho Escolar das dimensões criadas pelo grupo focal, da aprovação da implantação da CPA na escola e da Resolução no 001/2019), visando a nortear as atividades da CPA.

Dessa forma, reiteramos que a CPA é um subgrupo subordinado ao Conselho Escolar com a finalidade promover a reflexão-ação por meio de subsídios propiciados pela autoavaliação de cada dimensão construída, a fim de contribuir para o aperfeiçoamento dos processos avaliativos institucionais e tomada de decisões.

Logo, o objetivo da CPA é criar uma atmosfera para que a comunidade escolar forme, coletivamente, uma consciência sobre os indicadores que estão contribuindo para a construção do presente e do futuro institucional e daqueles que não estão correspondendo ao pleno andamento das atividades.

\section{plurais}


A criação de uma CPA deve ser pautada numa perspectiva social, mas sem, no entanto, excluir as avalições externas, pois, embora as avaliações externas estejam inseridas na qualidade total da educação, que é estritamente técnica; a qualidade social se propõe a efetivar avaliações de cunho técnico, mas também em caráter humano, político, social e de negociação.

É nesse sentido que, ao se propor a implantação e implementação de uma CPA, surge a necessidade de tecer reflexões sobre a qualidade da educação ofertada na escola, por isso, faz-se necessária a compreensão e aprofundamento dos termos dimensão, indicadores e parâmetros os quais servirão como subsídios para a composição de indicadores a serem propostos, auferidos e analisados por membros da CPA e validados pela comunidade escolar.

Para uma melhor compreensão desses termos, iremos discuti-los, a partir do nosso estudo de caso, sobre a implantação e implementação de uma CPA em uma escola da rede estadual de ensino, na cidade de Feira Nova, Pernambuco.

Anteriormente à implantação da CPA, nossos sujeitos de pesquisa, participantes do grupo focal, foram estudantes, professores e membros da equipe gestora, selecionados através de edital pelo Conselho Escolar da escola. Tiveram como objetivo discutir os resultados das avaliações internas e externas e suas implicações na qualidade da educação da escolar. Eles puderam refletir também sobre pontos cruciais à garantia da qualidade da educação da escola da qual fazem parte. Essas reflexões permitiram que os membros da CPA repensassem o significado dos termos dimensões, indicadores e parâmetros, os quais ganharam novos contornos nesta pesquisa.

\section{A construção de dimensões para autoavaliação da qualidade da educação pela CPA de uma escola da rede pública de ensino}

A educação como um processo abrangente deve ser observada a partir de várias configurações. Estas compõem as dimensões do espaço escolar por haver multiplicidade de aspectos que elencam a estrutura da organização, o planejamento escolar, os sujeitos e as práticas produzidas neste local.

Nesse sentido, a dimensão é uma construção de múltiplos aspectos que podem afetar a vida dos sujeitos, gerando inclusões, exclusões, conformismos e/ou transformações no âmbito escolar.

\section{plurais


As dimensões, na concepção em que será abordada neste texto, são importantes elementos da realidade escolar, sejam eles positivos ou negativos, os quais estão suscetíveis aos quatro pontos do ciclo PDCA (do inglês: Plan + Do + Check + Act).

Para dar conta destes pontos, as dimensões são mensuradas por indicadores e padronizadas por parâmetros.

Para entendimento da associação entre o ciclo PDCA e a construção de dimensões, indicadores e parâmetros, elaborados tanto por grupos focais (dimensões) e da CPA (indicadores e parâmetros). Em síntese, apresentamos a figura 1 para compreensão do ciclo DIP (Dimensões, Indicadores e Parâmetros) que constrói e se reconstrói quando necessário no âmbito educacional.

Figura 1: Ciclo da construção das Dimensões, Indicadores e Parâmetros ou Ciclo DIP

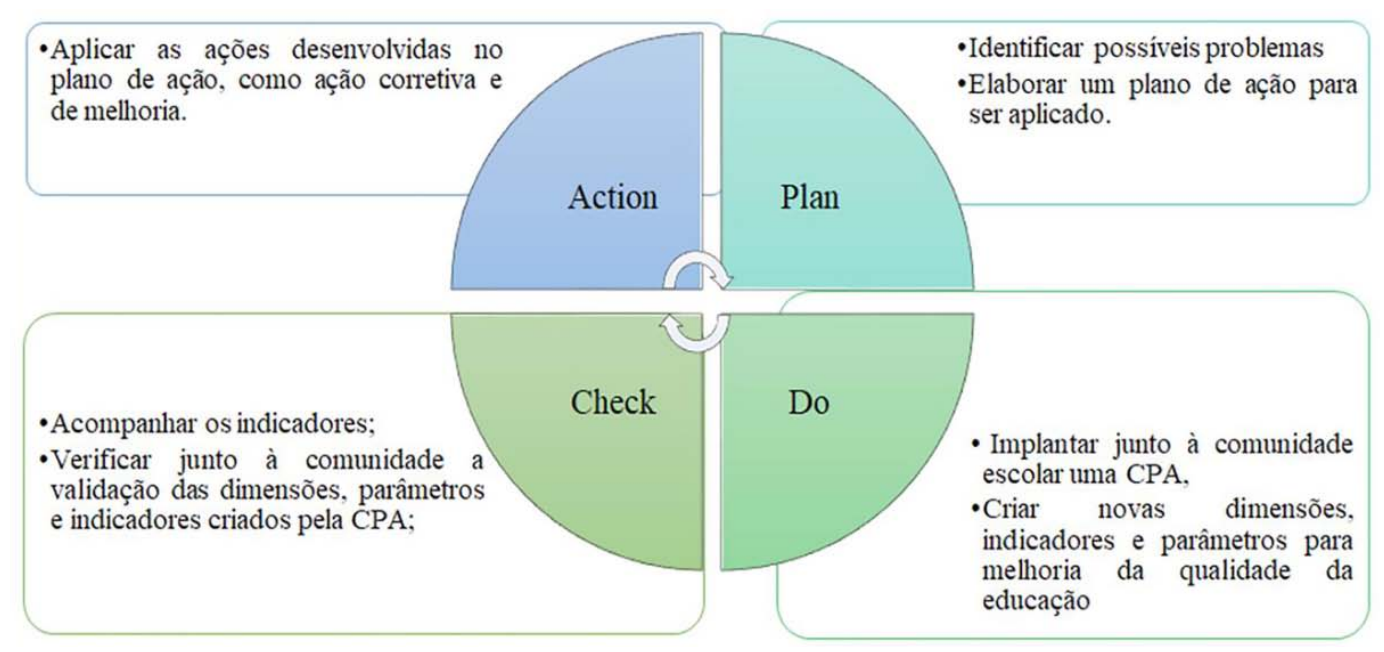

Fonte: Autoras, 2019.

Essas etapas referem-se à construção de cada elemento que está sendo tecido para pôr em prática a qualidade negociada na educação básica. Inicialmente, há um planejamento de ações, em seguida, a implantação destas no locus da pesquisa, análises constantes para validação do planejamento e execução das ações estabelecidas e avaliação das etapas anteriores para obtenção dos resultados esperados. Contribuindo, assim, para que as etapas sejam cíclicas e passíveis de ações corretivas, caso haja insucesso em alguma etapa.

\section{plurais}


No grupo focal, que constituiu o nosso estudo de caso, essas dimensões foram apreendidas tanto por seus aspectos estruturais de ensino-aprendizagem (avaliação interna), quanto a algumas dimensões da gestão escolar elencadas por Lück (2008) - gestão democrática e participativa de pessoas; pedagógica; administrativa; da cultura escolar; do cotidiano escolar e de resultados educacionais - e a enfoques de multiplicidade do itinerário formativo e das interações dos sujeitos, bem como outros aspectos que podem surgir de acordo com a realidade de cada espaço escolar.

As dimensões possibilitam a organização dos indicadores alternativos construídos pela CPA por agrupamentos de assuntos/conteúdos afins, mas que primam por um objetivo comum.

\section{Indicadores: da compreensão à concepção}

A concepção de indicadores deve ser antecedida de processos participativos que envolvam a comunidade educacional - estudantes, professores, funcionários e familiares - com vistas a compartilhar os saberes e as experiências daqueles que vivenciam os espaços, além de incorporar a reflexão sobre o perfil pedagógico da instituição, lócus da pesquisa.

Para compor indicadores da educação é necessário basear-se na escuta, no diálogo e na observação das necessidades e dos interesses expressos pelos sujeitos da comunidade escolar e transformar esses itens em objetivos pedagógicos que são propícios a mensurar os anseios daquela instituição de ensino.

Deponti et al. (2002, p. 46), afirmam que indicador "é um instrumento que permite mensurar as modificações nas características de um sistema”, ou seja, permite mensurar um sistema a partir de estabilidade, avanços ou insucessos. As características de um sistema referem-se às dimensões que estão sendo mensuradas por indicadores.

Lück (2009, p. 58) afirma que "o indicador vem a constituir-se no elemento mensurável que permite concluir que ocorreu um determinado resultado". O resultado pode ser obtido através da variação do indicador quando comparado a resultados anteriores.

Logo, as concepções de Deponti et al. (2002) e Lück (2009) se assemelham ao compreenderem indicador como um elemento/instrumento mensurável com vistas a variações de um sistema e/ou resultado.

\section{plurais}


A exemplo da concepção defendida por Deponti et al (2002) e Lück (2009) acerca do que compreendem por indicador, consta nos Parâmetros Nacionais de Qualidade da Educação Infantil definição semelhante às apresentadas por eles, quando versa que "indicadores presumem a possibilidade de quantificação, servindo, portanto, como instrumento para aferir o nível de aplicabilidade do parâmetro" (BRASIL, 2006a, p.08)

Bondioli (2004, p.18) esclarece que indicadores são "sinalizações, linhas que indicam um percurso possível de realização de objetivos compartilhados. (...) aquilo que os diferentes atores sociais (...) se empenham em buscar".

Freitas (2005, p.12) compreende que os indicadores:

(...) são importantes mais pela significação compartilhada que possuem perante os atores da escola que pelo valor numérico ou de análise que possam gerar. Os indicadores têm de ser uma construção social que se legitima e se desenvolve no interior da instituição escolar e têm seu lugar natural no curso da avaliação institucional, induzida e acompanhada pelas políticas públicas [...] (FREITAS, 2005, p.12)

A concepção de indicadores vai além de ser um elemento/instrumento que mensura algo, o que o torna tão importante é a forma como são desenvolvidos.

No chão da escola, a construção social e negociada de indicadores, através da partilha de anseios por melhorias é o que legitima a necessidade de se mensurar o sistema, a política pública, a instituição escolar.

Jannuzzi (2004, p.15) nos apresenta essa mesma percepção de forma mais elaborada, ao discorrer que,

Indicador é a medida, em geral, quantitativa dotada de significado social substantivo, usado para substituir, quantificar ou operacionalizar um conceito social abstrato, de interesse teórico (para a pesquisa acadêmica) ou programático (para a formulação de políticas). É um recurso metodológico empiricamente referido, que informa algo sobre um aspecto da realidade social ou sobre mudanças que estão se processando na mesma (JANNUZZI, 2004, p. 15). 
A ideia de mensurar o abstrato faz o indicador se tornar uma ferramenta capaz de modificar/ aprimorar o sistema educacional, quando acompanhado periodicamente, pois ele apresenta aspectos da realidade e seus impactos. Observados os impactos e as realidades, notar-se-á em que medida uma meta fora alcançada a partir do resultado do indicador.

Recomenda-se que a cada objetivo ou meta educacional defina o indicador, pelo qual se verificará a sua realização, isto é, "o elemento observável que permitirá verificar em que medida o objetivo ou meta foi realizado" (LÜCK, 2009).

Além disso, Freitas (2005, p.14) diz que "é importante frisar que a definição de indicadores, apesar das características locais que fortemente explicarão as dificuldades ou facilidades de realização, é estabelecida no conjunto das necessidades e dos compromissos do sistema público de ensino".

Para que as dimensões possam agrupar indicadores por afinidades e os indicadores possam ser auferidos é preciso que se tenham parâmetros para validar as ações propostas por cada indicador para que possam ser avaliadas como válidas, insuficientes ou inválidas. O parâmetro permite identificar se o indicador cumpriu a meta estabelecida para determinada dimensão.

\section{Parâmetros de qualidade da educação básica: noção, classificação e formulação}

Os indicadores, conforme vimos, servem para mensurar os parâmetros que, por sua vez, podem ser definidos como a norma, o padrão, ou a variável capaz de modificar, regular, ajustar o sistema. (HOUAISS e VILLAR, 2001).

Parâmetros podem ser definidos como referência, ponto de partida, ponto de chegada ou linha de fronteira. Indicadores presumem a possibilidade de quantificação, servindo, portanto, como instrumento para aferir o nível de aplicabilidade do parâmetro (BRASIL, 2006a).

Parâmetros são sinônimos de padrões de qualidade, enquanto indicadores mensuram a qualidade, desde respostas óbvias às mais complexas. Devido a essa complexidade, formular indicadores e parâmetros que subsidiem a constatação da qualidade da educação ofertada no âmbito escolar só se torna fidedigna quando há a participação dos sujeitos da escola.

\section{plurais


Por reconhecer os atores da comunidade escolar como sujeitos do processo educacional e como principais usuários do ambiente educacional, é necessário definir parâmetros essenciais que ofereçam a reflexão sobre as necessidades desses sujeitos que podem ter cunho psicológico, social, intelectual ou ambiental, através da relação harmoniosa com o entorno e da adequação dos ambientes internos e externos à escola.

Conforme Moreira (1996, p.11),

Os parâmetros constituem instrumento promotor da qualidade do ensino, já que se pretende que orientem e aperfeiçoem o trabalho pedagógico nas escolas. Consoante a tal intenção, propõem-se objetivos, conteúdos essenciais, critérios de avaliação e orientações didáticas.

Logo, a CPA, "ao consolidar os parâmetros, tem como objetivo apontar metas de qualidade que ajudem o estudante a enfrentar o mundo atual como cidadão participativo, reflexivo e autônomo, conhecedor de seus direitos e deveres" (BRASIL, 1997).

O ciclo DIP, apresentado na Figura 1, indicou os passos para a construção de dimensões, indicadores e parâmetros que nos possibilitaram, durante todo o processo, verificar os impactos oriundos desse percurso. Esses impactos serão apresentados através das impressões ocasionadas desde a concepção do grupo focal à implantação e implementação da CPA.

\section{Resultados e Análises: Impactos da implantação e implementação da CPA na escola}

Após a implantação da CPA, na escola, as reflexões tecidas permitiram aos membros da CPA validarem as dimensões criadas pelo grupo focal, ao mesmo tempo em que se vislumbrou a necessidade de construir indicadores alternativos que abranjam as concepções de Deponti et al. (2002), Freitas (2005), Bondioli (2004), Jannuzzi (2004) e Lück (2009) e parâmetros, conforme concepção e objetivos traçados, respectivamente, por Moreira (1996) e BRASIL (1997), que permitissem aos sujeitos da escola autoavaliar a qualidade da educação ofertada na escola, locus da pesquisa, a fim de garantir o padrão de qualidade da educação, conforme preconizam os art. 205, 209 e 214 da CF.

\section{plurais}


A problematização da construção de indicadores e parâmetros permitiu respondermos ao questionamento que norteou a construção desta pesquisa: quais indicadores alternativos de avaliação e monitoramento da qualidade da educação emergem a partir da criação de uma CPA na escola?

Durante o processo de criação de dimensões, indicadores e parâmetros realizados pela CPA, utilizamos o passo a passo do ciclo DIP (Figura 1). Isso permitiu aos membros da CPA elaborarem as dimensões necessárias à autoavaliação da escola, a saber: 1) prática pedagógica e avaliação, 2) multiplicidade de experiência formativa, 3) interações, 4) acesso e permanência dos alunos na escola, 5) promoção da saúde e integridade do ser, 6) gestão escolar democrática, 7) ambiente físico escolar, 8) formação e condições de trabalho dos profissionais da escola, 9) ensino-aprendizagem e 10) ambiente educativo, as quais estão diretamente ligados ao IDEPE e, em certo ponto, contribuem para a melhoria do resultado deste.

A exemplo, temos as dimensões 1, 5, 8 e 9, respectivamente: prática pedagógica e avaliação impacta nos resultados da avaliação do SAEPE e, consequentemente, no resultado do IDEPE, pois envolve planejamento, monitoramento e avaliação; abandono e permanência do estudante na escola, essa dimensão traz indicadores essenciais à composição do IDEPE, uma vez que se refere ao fluxo escolar; formação e condições de trabalho profissionais da escola, trata da formação de professores e a suficiência da equipe escolar, pontos cruciais para a definição do IDEPE e ensino-aprendizagem que contribui significativamente para a melhoria da proficiência do SAEPE e, consequentemente, do IDEPE.

Esses elementos nos permitem constatar que os quarenta indicadores alternativos de avaliação e monitoramento da qualidade da educação, bem como dos seus respectivos parâmetros, que emergiram a partir da criação de uma CPA na escola, foram oriundos da necessidade de um novo olhar sob a qualidade da educação da escola, locus da pesquisa, enfatizando o caráter humano, político, social da avaliação.

Uma vez criados os indicadores alternativos pela CPA, buscamos verificar as articulações possíveis entre os resultados obtidos pelos indicadores do IDEPE e pelos indicadores próprios, fomentados pela CPA, para acompanhamento do desempenho da escola, o que nos permitiu constatar que, embora os indicadores alternativos, oriundos das discussões da CPA, não estejam diretamente ligados ao IDEPE, em certo ponto, contribuem para a melhoria do resultado deste.

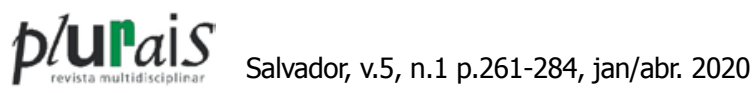


Sendo possível, inclusive, apontar os impactos na escola e para os próprios sujeitos envolvidos, a partir da elaboração dos parâmetros de qualidade que compõem a autoavaliação proposta pela CPA: a reflexão sobre o cotidiano da escola, ampliação de espaços de diálogo e de atuação dos estudantes, o empoderamento proporcionado tanto ao professor quanto ao estudante, à medida que todos participavam, contribuíam e eram ouvidos respeitosamente.

A implantação e implementação de uma CPA na escola, permitiu a ressignificação da noção de qualidade da educação desta instituição de ensino através da compreensão do Ciclo DIP. Na medida em que as ações do ciclo eram executadas, os sujeitos se apropriavam das variantes do termo qualidade da educação: qualidade total, qualidade negociada e qualidade social da educação, segundo as concepções de Mezomo (1997), Zitkoski (1997), Herédia (1997), Dourado (2007), Freitas (2005), Bondioli (2005), Peroni, (2006), Marchart (2007) e Brasil, (2010).

Esse processo permitiu a elaboração de dimensões, indicadores e parâmetros que resultou na criação de uma cartilha elaborada pela CPA, com base nos estudos realizados acerca da qualidade da educação, com ênfase na elaboração de indicadores próprios e alternativos para avaliar a qualidade da educação ofertada pela unidade escolar, localizada no município de Feira Nova

A participação ativa destes sujeitos em atividades que envolvem a coletividade tem sido o principal impacto social proporcionado por esta pesquisa, repensando, dessa forma, o lócus da pesquisa como uma escola democrática, segundo pressupõe Chizzotti (2020).

No que concerne às implicações desta pesquisa no âmbito da gestão escolar, podemos apontar as reflexões acerca da qualidade da educação, as avaliações externas e autoavaliação que podem ocorrer na escola sob diferentes prismas, segundo a concepção que a subsidia: qualidade total, qualidade social e qualidade negociada.

Promover o desenvolvimento de um olhar mais atento às dinâmicas da escola e às suas demandas formativas para a promoção de uma educação de qualidade permitiu aos sujeitos envolvidos nessa pesquisa de se apropriarem de conhecimentos sobre a qualidade da educação, função social da escola, resultados esperados da escola, dimensões, indicadores e parâmetros de avaliação e autoavaliação da qualidade da educação, para, assim, subsidiar a criação da Comissão Própria de Avaliação.

\section{plurais}


Implantada em 2019, essa CPA continua em atividade e o acompanhamento de sua evolução pode ainda nos oferecer ricos elementos de reflexão.

\section{Considerações Finais}

Por ser um espaço dinâmico, a escola deve ser avaliada não apenas com indicadores pré-estabelecidos, mas também em situações polissêmicas e incertas. Devem-se levar em conta as contradições, a pluralidade de pontos de vista, a diversidade dos sujeitos, e, segundo a sociologia, os elementos estruturais e conjunturais.

Sob esse enfoque, essa discussão consistiu em uma quebra de paradigmas, por vários aspectos: inicialmente, porque discorre sobre a qualidade da educação, um tema complexo e com inúmeras possibilidades de estudo e aplicações que rompem barreias; como também permeia algo muito presente nas escolas da rede estadual de ensino, o IDEPE (que é tido como o indicador que elevou o estado de Pernambuco ao patamar nacional de $1^{\circ}$ colocado no IDEB) e algo ainda mais desafiador: propor aos sujeitos da escola elaborarem os próprios indicadores e seus respectivos parâmetros. Isso implica uma abertura da gestão da escola e da Gerência Regional de Educação (órgão ao qual a escola está jurisdicionada), para o exercício de uma visão de gestão democrática, proporcionando adesão das ações dentro da escola e, principalmente, incentivar os sujeitos a se envolverem em propostas inovadoras para promover a qualidade da educação na escola.

Logo, esta pesquisa não propõe substituir ou desconsiderar as avaliações em larga escala, mas possibilitar a articulação dos indicadores próprios de avaliações externas a indicadores alternativos criados pela CPA, a fim de avaliar a qualidade da educação ofertada pela instituição de ensino em questão.

Portanto, é imprescindível elencar os impactos oriundos da pesquisa durante sua execução: impacto educacional, impacto propriamente social e o impacto cultural proporcionado por esta pesquisa. (BOUFLEUER, 2012).

Como impacto educacional observa-se a mobilização da comunidade escolar para a composição da CPA da escola, percebendo nela a possibilidade de ampliar o espaço de expressão, escuta e atuação de estudantes, professores e profissionais da educação dentro da escola.

\section{plurais}


Como impactos sociais da pesquisa, podemos destacar a formação de recursos humanos capazes de construir dimensões, indicadores e parâmetros, utilizando a ciência a serviço da educação.

Os impactos culturais podem ser percebidos pela adoção de novas práticas de apropriação e compartilhamento de significados sobre avaliação da qualidade da educação, implicando em práticas culturais que buscam melhorar o impacto da educação escolar na vida do estudante, a sistematização de conhecimentos que possam contribuir para a melhoria de vida na escola e da comunidade em seu entorno e a resolução de problemas cotidianos.

Por fim, problematizar a função social e politica da escola, através dos mecanismos de avaliação, pode ser um valioso instrumento para o aprimoramento da gestão educacional.

\section{REFERÊNCIAS}

BONDIOLI, A. O projeto pedagógico da creche e a sua avaliação: a qualidade negociada. Campinas: Autores Associados, 2004.

BOUFLEUER, José Pedro. Inserção social como quesito de avaliação da pós-graduação. Revista de Educação Pública, v. 18, n. 37, p. 371-382, 2012.

BRASIL. Ministério de Educação e Cultura. LDB - Lei nº 9394/96, de 20 de dezembro de 1996. Estabelece as diretrizes e bases da Educação Nacional. Brasília: MEC, 1996.

. Constituição (1988). Constituição da República Federativa do Brasil. Brasília: Senado Federal/Subsecretaria de Edições Técnicas, 2010.

. Constituição da República Federativa do Brasil de 1967. Disponível em: http://www. planalto.gov.br/ccivil 03/Constituicao/Constituicao67.htm Acessado em: 03 abr2020.

Ministério da Educação. Secretaria de Educação Básica. Parâmetros nacionais de qualidade para a educação infantil. Ministério da Educação. Secretaria de Educação Básica Brasília. DF. v.l, 2006.

CHISTÉ, Priscila de Souza. Pesquisa-Ação em mestrados profissionais: análise de pesquisas de um programa de pós-graduação em ensino de ciências e de matemática. Ciência \& Educação, v. 22 , n. 3, p. $789-808,2016$.

CHIZZOTTI, Antonio. As finalidades dos sistemas de educação brasileiros. Revista Educação em Questão. Natal, v. 58, n. 55, p. 1-19, e-19288, jan./mar. 2020.

\section{plurais}


COSTA, Anderson Gonçalves et al. Avaliação em larga escala no Brasil: entre a coordenação federativa e o ethos do Estado-avaliador. Revista Educação em Questão. Natal, v. 57, n. 51, p. 1-29, e-15806, jan./mar. 2019

CROSBY, Philip B. Qualidade é investimento. $3^{\mathrm{a}}$ ed., Rio de Janeiro, José Olímpio Editora, 1990.

DEMING, W. Edwards. Qualidade: A Revolução da Administração. Rio de Janeiro, Marques Saraiva, 1990.

DEPONTI, C.; ECKERT, C.; AZAMBUJA, J. L. B. de. Estratégia para construção de indicadores para avaliação da sustentabilidade e monitoramento de sistemas. Agroecologia e Desenvolvimento Rural Sustentável, v.3, n.4, p.44-52, 2002.

DONABedian, Avedis. La Calidad de la Atención Médica. México, La Prensa Médica Mexicana. S.A. de C.V., 1991.

DOOLEY, L. M. Case Study Research and Theory Building: Advances in Developing Human Resources (4), 335-354, 2002.

DOURADO, Luiz Fernandes. Políticas e Gestão da Educação Básica no Brasil: Limites e Perspectivas. (2007) Disponível em: http://www.scielo.br/pdf/es/v28n100/a1428100.pdf Acessado em janeiro de 2018.

DUARTE, C. Uma análise de procedimentos de leitura baseada no paradigma indiciário. Dissertação (Mestrado em Linguística). Universidade Estadual de Campinas (UNICAMP) / Instituto de Estudos da Linguagem, 1998.

FERRAÇO, Carlos Eduardo. Pesquisa com o cotidiano. Educação \& Sociedade, vol. 28, núm. 98, janeiro-abril, 2007, pp. 73-95. Centro de Estudos Educação e Sociedade. Campinas, Brasil. Disponível em: http://www.scielo.br/pdf/es/v28n98/a05v2898.pdf_Acessado em 03ago 2018.

FLICK, U. Entrevista episódica. In: GASKEL, G.; BAUER, M. W. (Org.). Pesquisa qualitativa com texto, imagem e som: um manual prático. Petrópolis: Vozes, 2002. p. 114-136.

FONSECA, J. J. S. Metodologia da pesquisa científica. Fortaleza: UEC, 2002.

FREITAS, Luiz Carlos de. Qualidade Negociada: Avaliação e contra regulação na escola pública. Educ. Soc., Campinas, vol. 26, n. 92, p. 911-933, Especial - Out. 2005 Disponível em

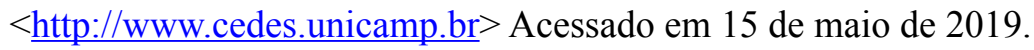

\section{plurais}


GASKEL, G.; BAUER, M. W. (Org.). Pesquisa qualitativa com texto, imagem e som: um manual prático. Petrópolis: Vozes, 2002.

GOLDENBERG, M. A arte de pesquisar. Rio de Janeiro: Record, 1997.

GOMES, M. E. S.; BARBOSA, E. F. A técnica educativa de grupos focais para obtenção de dados qualitativos. Educativa, 1999. Disponível em: http://www.tecnologiadeprojetos.com.br/ banco_objetos/\%7B9FEA090E-98E9-49D2-A638-6D3922787D19\%7D Tecnica\%20de \%20 Grupos\%20Focais\%20pdf.pdf. Acesso em: 26jan2018.

GONDIM, Sônia Maria Guedes. Grupos focais como técnica de investigação qualitativa: desafios metodológicos. 2002. Disponível em: http://www.scielo.br/pdf/paideia/v12n24/04 Acessado em abril de 2018 .

HERÉDIA, Vânia Beatriz Merlotti. Dilemas e globalização. In: Qualidade em educação: um debate necessário. Passo fundo: Universidade Educação Básica, Série: Interinstitucional. 1997.

HOUAISS, Antônio; VILLAR, Mauro de Salles. Dicionário Houaiss da língua portuguesa. Rio de Janeiro: Objetiva, 2001.

JANNUZZI, P. de M. Indicadores sociais no Brasil: conceitos, medidas e aplicações. 3. ed. Campinas: Alínea; Campinas: PUC, 2004.

LATORRE, Antônio. La Investigación Accion: Conocer y cambiar la práctica educativa. Editora Graó: España, 2003.

LÜCK, Heloisa. Dimensões de gestão escolar e suas competências. Curitiba: Editora Positivo, 2009.

MARCHART, Oliver. Post-foundational Political Thought: political difference in Nancy, Lefort, Badiou and Laclau. Edinburgh: Edinburgh University Press, 2007.

MEZOMO, João Catarin. Gestão da qualidade total na escola: Princípios básicos. Petrópolis: Vozes, 1997.

MINAYO, M. C. S. (Org.). Pesquisa social: teoria, método e criatividade. Petrópolis: Vozes, 2001.

MOREIRA, Antônio Flávio Barbosa. Os Parâmetros Curriculares Nacionais em questão. Educação \& Realidade, jan/jun 1996. Disponível em: file:///C:/Users/ESCOLA/Downloads/71637-297206-1-PB.pdf. Acessado em 14 de maio de 2019. 
PERNAMBUCO. ALEPE. Lei no 11.014 de 28 de dezembro de 1993. Disponível em:http:// legis.alepe.pe.gov.br/texto.aspx?id=6262\&tipo=TEXTOORIGINAL Acessado em 03 de agosto de 2018.

PERONI, Vera. Reforma do Estado e a tensão entre o político e o privado. P Alegre: UFGS, 2006.

THIOLLENT, M. Metodologia da pesquisa-ação. São Paulo: Cortez, 2011.

YACUZZI, E. El estudio de caso como metodologia de investigación: teoría, mecanismos causales, validación. (Serie Documentos de Trabajo, 2005). Disponível em: http://www.cema.edu. ar/publicaciones/download/documentos/296.pdf. Acessado em: 06jul2019.

YIN, R. Estudo de Caso: Planejamento e Métodos. Porto Alegre: Bookman, 2005.

ZITKOSKI, Jaime José. Educação de qualidade: que qualidade queremos? In: Qualidade em educação: um debate necessário. Passo Fundo: Universidade Educação Básica, Série: Interinstitucional. 1997.

Recebido em: 30 de março de 2020 .

Avaliado em: 10 de maio de 2020.

Esta obra está licenciada com uma Licença Creative Commons Atribuição 4.0 Internacional. 